\title{
GERINDO A TRANSIÇÃO: ESTRATÉGIAS DE EXPLORAÇÃO NO PROCESSO PARA SER LIDER
}

\author{
MANAGING TRANSITION: EXPLORATION STRATEGIES IN THE PROCESS TO BE \\ A LEADER
}

Bernardo Almeida1 Catarina Brandão²

1 Instituto Universitário da Maia, Departamento de Psicologia, Portugal, e-mail: bernardomfca@gmail.com

2 Faculdade de Psicologia e de Ciências da Educação da Universidade do Porto. Centro de Psicologia da Universidade do Porto, Portugal, e-mail: catarina@fpce.up.pt

\author{
ART ICLE INFO \\ Article history: \\ Received 2020-01-15 \\ Accepted 2020-04-10 \\ Available online 2020-04-10
}

Palavras-chave: Liderança. Processo de transição. TABEIS. Comportamento exploratório.

Keywords: Leadership. Transition process. TABEIS. Exploratory behavior.

RESUMO. Este estudo tem por objetivo conhecer a vivência do processo de transição para um posto de liderança, explorando e descrevendo as estratégias que os indivíduos adotam para manter ativo o seu comportamento exploratório durante o processo. A investigação tem por base uma metodologia qualitativa, com recurso a entrevistas de história de vida, operacionalizadas em dois momentos. Os dados revelam as seguintes estratégias para manter ativo o comportamento exploratório: desenvolver competências; atividades de relaxamento; autorreflexão; estar próximo dos colaboradores; e suporte de familiares, amigos e pares. Baseado na Theory of Attachment Based Exploratory Interest Sharing, o estudo assume a importância de se investir na análise das dinâmicas exploratórias e desenvo/vimentais dos líderes e dos seus contextos com vista a potenciar a qualidade e a eficácia da liderança nas organizações.

ABSTRACT. This study aims to explore the experience of the process of transition to a leadership position, focusing on the strategies that leaders adopt to keep their exploratory behavior active during the transitioning process. The research adopts a qualitative methodology, with life history interviews, in two separate moments. The data reveal the following strategies to keep exploratory behavior active: developing skills; relaxation activities; self-reflection; being close to employees; and support from family, friends, and peers. Based on the Theory of Attachment Based Exploratory Interest Sharing, the study assumes the importance of investing in the analysis of the exploratory and developmental dynamics of leaders and their contexts to enhance the quality and effectiveness of leadership in organizations.

\section{Introdução}

A liderança é uma realidade dinâmica e pluridimensional em contínuo desenvolvimento, na qual importa integrar diferentes elementos e a satisfação coerente de todos (SVENINGSSON; ALVESSON, 2003). Sendo a liderança um fenómeno que tem que ver com interações entre pessoas, nos últimos anos os temas tipicamente humanos 
(autenticidade, conexão, realização, bem-estar) têm vindo a assumir uma natural importância no mundo do trabalho e das organizações.

Os desafios na liderança são inúmeros, assim como são múltiplos os estudos que se debruçam sobre o tema da liderança nas mais diversas dimensões (GAITER, 2013; GORDON; YUKL, 2004; ILIES; NAHRGANG; MORGESON, 2007; VINCE, 2004). Entre os desafios que os líderes enfrentam, um que se destaca e acerca do qual pouco se sabe, prende-se com a transição para um novo posto de liderança. Considerando a ausência de conhecimento acerca deste processo (SANTOS; PERES; BRANDÃO, 2018), desenvolveu-se uma investigação com o objectivo de explorar e descrever esse processo, considerando o «modo como os indivíduos vivenciam a sua situação no seu contexto, consigo e com os outros» (ALMEIDA; BRANDÃO, 2019). Este artigo apresenta um recorte desse trabalho, focando as estratégias adoptadas por indivíduos em processo de transição para uma posição de liderança, de forma a manter activo o seu sistema exploratório.

\section{Teoria da vinculação e TABEIS}

Tendo por base o trabalho desenvolvido por Bowlby, a Theory of Attachment Based Exploratory Interest Sharing (TABEIS) conceptualiza o funcionamento do self como um sistema de sistemas interrelacionados: careseeking, caregiving, partilha de interesses, afeto e sexualidade, defesa do self, ambiente interno e ambiente externo (HEARD; LAKE, 1986; MCCLUSKEY, 2005). Estes sete sistemas são ajustados por objetivos, sendo seis deles suportados biologicamente (só não o é o sistema de ambiente interno). Estando o sistema regulado, o comportamento exploratório do indivíduo mantém-se ativo (HEARD; LAKE, 1997) e, assim, o indivíduo está em condições propícias para conhecer novas realidades, realizar novas aprendizagens, evoluir como humano interna e externamente. O comportamento exploratório promove relacionamentos e interesses, fortalece a competência e autonomia, robustece a autoestima. No fundo, permite acontecer a natural propensão dos humanos para se realizarem por meio da sintonia genuína dos relacionamentos (MCCLUSKEY, 2005).

$\mathrm{Na}$ medida em que o sistema de vinculação se desenvolve reguladamente, assim se expande a janela de tolerância e o respetivo potencial de desenvolvimento pessoal, social e profissional. Ora, a janela de tolerância refere-se à área de ativação emocional (entre a hiper e a hipo ativação) propícia ao comportamento exploratório. Deste modo, a autorregulação, ao modular a ativação e a avaliação do significado, promove a criação e o desenvolvimento de competências coerentemente (SIEGEL, 1999). Por conseguinte, o apoio dado por alguém que assume o papel de cuidador (sendo, assim, uma fonte de suporte), e que na linguagem da TABEIS se designa de Caregiver (CG), a alguém que (mais ou menos explicitamente) procura apoio (i.e., cuidado ou suporte), e que na linguagem da TABEIS se designa de Careseeker 
(CS), condiciona a qualidade exploratória deste último. Tanto assim que, com base nas sucessivas interações, em especial com principais figuras de vinculação na infância (BOWLBY, 1969/1997; 1973/1998; 1980/1998), são construídos Internal Models of the Experience of Attachment (IMEARs) (HEARD; LAKE, 1997), que são modelos de como essas relações aconteceram e de previsão de como outras possam acontecer. Traduzem representações relativas ao self (o seu valor) e aos outros (a sua responsividade). Entendase o self de um modo interpessoal, sendo experimentado nas dinâmicas exploratórias e nos processos defensivos por meio das relações como um sistema de sistemas interdependentes e com vista ao bem-estar e à competência (HEARD; LAKE; MCCLUSKEY, 2012).

Quando a procura de apoio é satisfeita, o sistema medo é regulado, o comportamento exploratório permanece ativo e a pessoa está a cuidar de si e dos outros. Neste sentido, entende-se o Goal Corrected Empathic Attunement (GCEA) como expressão dos tipos de interação que regulam o sistema de vinculação. É restaurador o padrão que empaticamente compreenda o CS e com ele ative o comportamento exploratório (MCCLUSKEY, 2005). Assim, através de GCEA é possível evoluir nos padrões de vinculação e melhorar o bem-estar intrapessoal, interpessoal e profissional. Aliás, um dos principais contributos da TABEIS resulta precisamente do facto de entender e de trabalhar o self a partir da exploração da partilha de interesses (HEARD; LAKE; MCCLUSKEY, 2012).

\section{Vinculação e liderança}

Os líderes desempenham um papel crucial ao integrar e equilibrar as necessidades dos seus subordinados nas organizações (BRANDÃO; HENRIQUE; MIGUEZ, 2016). O modo como constroem a sua relação com os subordinados não é sempre igual e depende de diferentes variáveis (personalidade, disponibilidade, energia, tempo e recursos), expressando-se por isso em diferentes qualidades de relacionamentos e em distintos benefícios para a organização (POPPER; MAYSELESS, 2003). Importa, por isso, considerar, por um lado, os diferentes padrões de relação entre líder e subordinado e, por outro, o processo entre dois selves que se influenciam mutuamente nessa relação, sendo que o líder, como a figura de vinculação, tem por múnus ser guia, ou seja, ser caregiver. Logo, um bom líder é um elemento de apoio, responsivo e promotor da autonomia do subordinado que, ao reconhecer no líder competência e disponibilidade para o ajudar, desenvolve com ele uma relação de confiança, na qual procura apoio. Para tal, importa que o líder não ative os seus sistemas de careseeking e de defesa do self, que uma vez ativados podem prejudicar as interações e as metas no exercício da liderança (BRANDÃO; HENRIQUE; MIGUEZ, 2016).

De facto, uma das tarefas mais decisivas na organização é a de construir relações de trabalho que valorizem cada pessoa, equilibrem níveis de influência e trabalhem em conjunto objetivos, prioridades e expectativas. Neste processo de construção, com altos e baixos, o 
modo como essas relações são trabalhadas em conjunto produz toda a diferença na organização (GABARRO; ATHOS, 1976). Tanto assim é que os líderes que assumem uma atitude transformadora valorizam os subordinados em três principais áreas: instrumental (competências), interpessoal (confiança) e moral (valores). Esta dinâmica assume uma dimensão psicológica e integra um conjunto de processos que permitem aos líderes gerar motivação e valor nos subordinados (POPPER; MAYSELESS, 2003). Por tudo isto, importa atentar a dinâmica desenvolvimental do líder (ORVIS; RATWANI, 2010).

\section{O que acontece quando se transita para uma posição de liderança?}

Pouco se sabe sobre o processo de transição para uma posição de liderança, sendo que o trabalho desenvolvido por Santos, Peres e Brandão (2018) sugere que este processo integra três fases: aprendizagem, autonomização e consolidação. Apesar de ao longo do processo de transição os líderes se depararem com diferentes valores, atitudes, situações e expectativas, que podem, naturalmente, gerar diferentes medos (BARKOULI, A., 2015), muitos líderes não revelam esses medos, por crerem que isso é sinal de fraqueza (SALOVEY; MAYER, 1990). Contudo, a partilha emocional através de uma comunicação autêntica potencia o êxito pessoal e organizacional (ÖHMAN, 2008). É óbvio que a capacidade para lidar com este processo, de um modo adaptativo, é essencial para o desenvolvimento pessoal e organizacional, pois nele integram-se variáveis contextuais e psicológicas, das quais resulta a mobilização da motivação, da comunicação, da colaboração, dos recursos mentais e emocionais e das ações que requer determinada situação (WOOD; BANDURA, 1989). Sabendo nós que a ativação do sistema de defesa do self condiciona a ação dos líderes (competência, desempenho e bem-estar), na medida em que inibe a sua exploração e a criatividade (BRANDÃO; HENRIQUE; MIGUEZ, 2016), importa atender às estratégias que mantenham ativo o comportamento exploratório dos líderes, perceber aquilo que os leva a mobilizar essas estratégias e como estas são experienciadas.

Ora, este estudo tem precisamente por objetivo o de descrever a ativação do sistema de exploração dos líderes quando transitam para uma posição de liderança. Procura, assim, aprofundar a compreensão acerca dessa dinâmica e contribuir para que os líderes melhor cumpram a sua missão. Com efeito, estes são particularmente chamados a desenvolver a consciência de si e a incrementar a qualidade das interações na organização, reconhecendo a influência que os outros têm neles, que eles têm nos outros, e como as experiências passadas se integram nesse processo. Consideramos, conforme a evolução da compreensão da liderança tem vindo a mostrar, que os valores humanos serão cada vez mais reconhecidos como estando na base da vida das organizações, e que estas cada vez mais se nutrirão não de ideais de sobrevivência, como a obsessão dos resultados pode indicar, mas sim de 
dimensões desenvolvimentais, como o bem-estar, a autenticidade e a partilha.

\section{Método}

Procedeu-se a um estudo exploratório qualitativo (SANDELOWSKI, 2001), com a seguinte questão de investigação: quais as estratégias adoptadas pelos indivíduos para manter ativo o seu comportamento exploratório, quando se encontram a transitar para uma posição de liderança? Através de uma análise indutiva, procura-se interpretar os significados, as emoções e as vivências dos participantes tendo em conta o foco de estudo.

\subsection{Participantes}

Os dados foram recolhidos junto de cinco indivíduos em posição de liderança. O critério de inclusão estabelecido foi terem iniciado o processo de transição para uma posição de liderança há menos de um ano. Conscientes dos limites, optámos por participantes do sexo masculino por um motivo único: o estudo está integrado num grupo de investigação alargado a outros temas. O critério de um ano procurou captar, pela recentidade, memórias e emoções ainda vivas concernentes aos desafios que uma nova missão de liderança determina nas organizações. Ao longo da investigação assumimos que os participantes são os especialistas, os intérpretes e os agentes responsáveis pelo seu desenvolvimento, percebido como um itinerário de coconstrução, adaptação e integração de modelos internos progressivamente mais evoluídos (FONSECA; ARAÚJO; SANTOS, 2012). A Tabela 1, abaixo, caracteriza sumariamente os participantes.

Tabela 1 - Caracterização dos participantes

\begin{tabular}{|c|c|c|c|c|c|c|c|}
\hline & \multicolumn{3}{|c|}{ Dados socio-demográficos } & \multicolumn{4}{|c|}{ Dados socio-profissionais } \\
\hline Participante & Idade & Escolaridade & $\begin{array}{c}\text { Estado } \\
\text { civil }\end{array}$ & $\begin{array}{c}\text { Antiguidade } \\
\text { na } \\
\text { organizaçao }\end{array}$ & $\begin{array}{l}\text { Antiguidade } \\
\text { na função }\end{array}$ & $\begin{array}{c}\text { Função } \\
\text { atual }\end{array}$ & $\begin{array}{c}\text { Quantas } \\
\text { pessoas } \\
\text { lidera }\end{array}$ \\
\hline P1 & $31-35$ & $12 .^{\circ}$ ano & casado & $11-15$ anos & 10 meses & $\begin{array}{l}\text { adjunto } \\
\text { do } \\
\text { gerente }\end{array}$ & 31 a 35 \\
\hline P2 & $31-35$ & licenciado & casado & 6-10 anos & 3 meses & gerente & 56 a 60 \\
\hline P3 & $21-25$ & mestrado & solteiro & $1-5$ anos & 2 meses & gerente & $\begin{array}{c}121 \mathrm{a} \\
130\end{array}$ \\
\hline P4 & $26-30$ & licenciatura & solteiro & $1-5$ anos & 10 meses & $\begin{array}{l}\text { adjunto } \\
\text { do } \\
\text { gerente }\end{array}$ & 51 a 60 \\
\hline P5 & $26-30$ & 12..$^{\circ}$ ano & casado & 11-15 anos & 9 meses & gerente & 51 a 60 \\
\hline
\end{tabular}

Nota. Idade em anos. Fonte: O autor (2020). Sempre que possível recorreu-se a intervalos nas variáveis, de forma a melhor assegurar o anonimato dos participantes. 


\subsection{Técnica de recolha de informação}

Optou-se pela técnica da história de vida para melhor se captar o fenómeno em estudo (PAULILO, 1999), por entendermos que os benefícios desta técnica são particularmente relevantes quando se foca a população dos líderes. Especificamente, convoca os líderes a falar da sua experiência, propicia uma melhor aproximação à realidade e uma diminuição de preconceitos; possibilita a exploração de dinâmicas emocionais; valoriza os dados dos participantes de um modo operativo e não só responsivo; e, ainda, enriquece o estudo com níveis de profundidade que de outro modo dificilmente seriam alcançados (EDVARDSSON, 1992). Assim, visou-se compreender as representações, as atitudes e as crenças subjacentes aos líderes nas suas dinâmicas intrapessoais e interpessoais no quadro da organização.

No seio da metodologia qualitativa, as abordagens biográficas (história oral, biografias, autobiografia e história de vida) dedicam-se à recolha e ao estudo sistemático de documentos que descortinam momentos-chave na vida dos sujeitos (AMADO, 2014). A história de vida destaca-se pela qualidade da relação entre investigador e observado que se pretende alcançar (SILVA; BARROS; NOGUEIRA; BARROS, 2007) como meio privilegiado para devolver ao indivíduo a possibilidade de reconstruir a sua história de vida. Na verdade, a partir da narrativa do participante privilegiam-se as dimensões que normalmente escapam às abordagens quantitativas, dando ênfase ao que é particular, individual, único (BRANDÃO, 2007). Neste sentido, servimo-nos de um guião de entrevista como suporte para a primeira entrevista, para que cada participante explanasse a sua história integrada nos temas da investigação. O guião é composto por quatro principais secções, para além das questões de caracterização do participante (dados socioprofissionais e sociodemográficos): percurso profissional anterior, processo de transição, posição atual e estratégias adotadas para potenciar a liderança. O guião foi submetido a pré-teste com reflexão falada, de forma a testar a atitude do entrevistador, sobretudo no que concerne à empatia e neutralidade, e avaliar a necessidade de alterações às questões colocadas.

\subsection{Procedimentos de recolha}

Após se explicar o estudo e os seus objectivos, a organização que aceitou colaborar no estudo identificou trabalhadores que cumpriam os critérios de inclusão definidos. Foi enviado a esses indivíduos um e-mail com o pedido de colaboração no estudo, explicando o propósito do estudo, assim como as exigências éticas e sigilosas a que nos comprometíamos. De acordo com as possibilidades de cada líder, foram agendadas as entrevistas, que se realizaram num mesmo espaço físico da organização, tendo os participantes se deslocado para esse espaço.

As entrevistas demoraram, em média, uma hora, e foram gravadas em formato de 
áudio, com autorização dos participantes. As respetivas transcrições foram posteriormente enviadas aos participantes, de forma a que cada um validasse a sua e esta servisse de base para a segunda entrevista. Esta realizou-se cerca de vinte dias após a primeira, desta feita fora da organização e em lugares informais (e.g., café, restaurante, sala de estar), de modo a criar condições propícias para que os participantes se pudessem exprimir o mais natural e autenticamente possível, sem nenhum tipo condicionamento em relação ao seu ambiente de trabalho. Nesta segunda entrevista o entrevistador também se apoiou na transcrição da primeira entrevista, que possuía anotações em vista de um estudo mais focado e profícuo.

Procurou-se que em ambos os momentos a partilha dos participantes fosse a mais genuína possível e, para isso, o papel do entrevistador foi o de ajudar os participantes a expressar o seu pensamento, discurso, emoção e ação. Na realidade, as entrevistas foram espaços de investigação, onde se deu primazia à relação empática, com a consciência da sua importância para a disponibilidade e o envolvimento dos participantes. Todos os participantes assinaram um consentimento informado aquando a primeira entrevista.

\subsection{Análise de informação}

As entrevistas foram exploradas com recurso à análise de conteúdo categorial (BARDIN, 2011). O corpus de análise é constituído pelas entrevistas transcritas e elegeu-se o tema como unidade de registo. Inclui-se nos dados a experiência havida no contato personalizado com cada um dos participantes, integrando o seu comportamento não verbal, entoação, níveis de ativação, entre outros parâmetros. De frisar ainda que para potenciar a exploração de informação, recorreu-se ao NVivo11 (QSR), software de suporte aos métodos qualitativos, onde foram introduzidos, geridos e analisados os dados.

Num primeiro momento verificou-se se o material transcrito correspondia ao proferido pelos participantes, avançando-se posteriormente para uma leitura aprofundada dos dados. O formato oral escrito facilitou o aprofundar do conteúdo das entrevistas, definindo-se o sistema de categorias (temas relevantes que, por serem semelhantes, constituem um grupo), que serviu de base ao processo de codificação (integração dos dados em cada uma das categorias), garantindo-se o nome e a definição operacional de todas as categorias (BRANDÃO, 2010). Para assegurar a qualidade das inferências da investigação foram considerados os critérios definidos por GUBA e LINCOLN (1994).

\section{Apresentação e discussão dos resultados}

De seguida apresentam-se e discutem-se os resultados obtidos, focando as estratégias adoptadas pelos líderes para manter ativo o comportamento exploratório. Assim, foram identificadas cinco principais estratégias a que os líderes recorrem para manter ativo o seu comportamento exploratório: desenvolver competências; atividades de relaxamento; 
autorreflexão; estar próximo dos colaboradores; suporte de familiares, amigos e pares.

\subsection{Desenvolvimento de competências}

Num olhar de conjunto, começamos por verificar que os líderes recorrem a várias atividades em ordem a desenvolver as suas competências enquanto líderes e que confirmam a importância que a capacitação de líderes tem em ordem à promoção da qualidade das suas experiências e dinâmicas profissionais, conforme atestam diversos estudos (ORVIS; RATWANI, 2010; SVENINGSSON; ALVESSON, 2003). Neste âmbito, uma das atividades desenvolvidas pelos participantes refere-se à formação, observando-se que todos integraram formações na organização, focando a gestão grupal e motivacional dos subordinados. Outra atividade que todos referem realizar é ler. No que concerne ao tipo de leitura, encontramos referência a textos mais científicos (e.g., P4), assim como a textos que nos remetem para o culto do líder enquanto ser excepcional (e.g., P1 e P2) e, ainda, textos que poder-se-áo aproximar mais a "receitas" de como fazer (e.g., P5).

«Gosto de ler aquelas entrevistas de pessoas que inspiram [...]; basicamente é isso» (P1)

«Não são propriamente livros sobre a liderança, mas [sobre o] modo como levavam a vida» (P2)

"Gosto muito de ler alguns textos sobre liderança [...]; diria que o meu grande recurso é a leitura» (P3)

«Vim de uma formação [...]; claro que essas formações nos dão skills» e lê "psicanálise ao nível do eu, estratégias internas e o modo como gerir a personalidade dos outros" (P4)

«De ler, não ao nível de livros; ler na internet, formas de liderar, o que é um chefe e um líder; vejo que há coisas que posso aplicar de outra forma para liderar melhor» (P5)

A descrição destas atividades e os dados globais das entrevistas sugerem que os líderes participantes neste estudo não recebem formação sobre a regulação interna das próprias emoções no contexto do trabalho, uma área que importa trabalhar (BARKOULI, AL, 2015). Note-se, ainda, que nenhum dos participantes hesita em afirmar que, mais do que os livros, é a experiência a principal mediação que os habilita como líderes, o que nos remete para a pertinência dos modelos de liderança mais de estilo do que de traços.

«marcaram-me mais as experiências do que os livros propriamente» (P2)

\subsection{Atividades de relaxamento}

Outra estratégia são as atividades de relaxamento, que se manifestam de dois principais modos: por um lado, as técnicas de respiração; por outro, as atividades de lazer. Ambas surgem como uma forma de, face às atividades diárias e problemáticas delas decorrentes, permanecer disponível para ajudar e motivar os trabalhadores e para o próprio líder manter-se disponível e motivado para melhor concretizar a sua missão. E quando as 
atividades de relaxamento não são referidas, encontramos algo próximo, que se traduz num espírito de apaziguamento (e.g., P1) que se procura manter e por meio do qual se pretende também fortalecer a dedicação à missão.

\begin{abstract}
«Primeiro dou uma volta, tento acalmar-me, tenho de sentir-me primeiro calmo [...]. Importa acalmar, primeiro serenar» (P1)

«Procuro levar as coisas com mais calma, mesmo se nem sempre é fácil gerir, pois é impossível não pensar nas coisas, não ficar afetado por elas» (P2)

«Tenho caminhado muito [...], sei que isso potencia a minha ação (...) tento pensar, tentar respirar» ... «preciso de dormir mais [...], o desgaste é bem maior [...]» e jogar ténis «contra a parede... é terapêutico. Quando estou no ténis é um mundo à parte, não me lembro de mais nada. Alivia, facilita o tal equilíbrio» (P3)
\end{abstract}

Note-se que P2 e P4 não se referem explicitamente a uma estratégia, mesmo que P4 tenha sido o participante que revelou no discurso em contexto de entrevista um maior nível de ativação emocional. Tendo em conta a literatura (GREENBERG, 2011) e o que se percebeu no processo de recolha de dados, o relaxamento pode traduzir-se numa ótima ferramenta fortalecedora do comportamento exploratório. Contudo, esta estratégia pode também surgir como um instrumento de contenção emocional com prejuízos inerentes para todos os envolvidos. Ou seja, o facto de os líderes tenderem a reservar e a não manifestar as suas emoções pode traduzir-se num maior cansaço, numa menor capacidade empática, numa menor disponibilidade de suporte aos subordinados, entre outros potenciais inconvenientes.

«Em casa torno-me mais irritado, sendo a casa um depósito emocional para mim» (P3)

\title{
6.3 Autorreflexão
}

A autorreflexão surge como outra estratégia assumida por todos os participantes no estudo. Trata-se de um exercício mental que acontece antes ou depois de as coisas acontecerem, no sentido de preparar a acção ou de conferir sentido ao acontecido (nomeadamente com recurso à relativização). Deste modo, e alinhado com o facto da autoreflexão ser uma entre as principais ferramentas que os líderes utilizam no exercício da sua missão (GAITER, 2013; VINCE, 2004), os participantes destacam a dimensão racional e o sentido das coisas quando falam das suas ações. Note-se, por exemplo, que P1 sublinha que, perante as situações que possam condicionar o seu processo exploratório, o exercício mental de relativização e de avaliação é importante na sua missão.

\footnotetext{
«Penso no modo como as coisas podem ser melhores, por exemplo, através da autorreflexão», e acrescenta: «fico sentado mais sozinho a pensar [...] como posso encontrar a solução» (P1)

«autorreflexão diária que importa fazer sobre a nossa liderança para perceber o que fizemos bem (...) quando vou no carro a caminho do trabalho, não ouço rádio, focome, procuro concentrar-me» (P2)

«no fundo faço muitas perguntas a mim mesmo, pergunto-me sempre muito antes de falar e ponho-me do outro lado", sublinhando "tenho de ir para casa e encontrar soluções» (P3)

«dar sentido certo às coisas, e o segredo é relativizar, ver as coisas como são» (P4)
} 
«De um modo automático [...] o que é que daqui pode correr mal? O que é que daqui pode resultar em conflito depois desta atitude?» «muitas vezes sinto a necessidade de me colocar à parte e pensar comigo mesmo de modo a encontrar soluções (...) a única coisa que tenho é parar para pensar, auto-ouvir, e reflito comigo; seria assim a minha única prática» (P5)

Paradoxalmente, quando os participantes se referem aos subordinados, valorizam o acompanhamento emocional. Em resumo, no trato consigo, os lideres em transição privilegiam a esfera racional, enquanto no trato com os subordinados, valorizam a dimensão racional e a emocional de igual forma.

\subsection{Estar próximo da equipa}

Outra estratégia identificada por todos os líderes tem que ver com o estar próximo dos subordinados. Efetivamente, os estudos revelam a importância que a proximidade empática dos líderes aos seus subordinados pode traduzir no que concerne ao desenvolvimento pessoal e profissional dos seus colaboradores (MCCLUSKEY, 2005; POPPER; MAYSELESS, 2003). Neste sentido, os participantes destacam a sua proximidade aos seus subordinados de dois principais modos: envolvimento empático (colocar-se no lugar do subordinado, validando-o emocionalmente) e envolvimento operativo (ajudar o subordinado nas tarefas), sendo que a primeira se destaca claramente. Ou seja, os líderes dão mais importância à envolvência emocional do que à realização de tarefas em conjunto. Portanto, de novo se verifica que a relevância que os líderes dão à dimensão emocional no relacionamento com os subordinados não corresponde à valorização que dão à sua própria coerência emocional (GAITER, 2013).

«o principal de um líder é ser atento a tudo, ver as pessoas, saber se se estão a sentir bem", destacando a importância de uma proximidade operativa: "gosto muito de ajudar as outras pessoas a aprenderem» (P1)

«é fundamental o acompanhamento dado às pessoas no sentido de que elas percebam que podem contar conosco» (P2)

"saber como a pessoa está; a ligação é muito importante, as pessoas saberem que nós estamos com elas (...) elas preferem esse sentimento à simples presença física» (P3)

«tento acompanhá-los (...) acumulamos muitas fontes de stress que são desnecessárias. Porque às vezes não sabemos [referindo-se aos subordinados] e não temos a coragem de pedir ajuda, estamos inseguros e ficamos calados» (P4) "gosto de estar a par das pessoas e ajudar, gosto de estar dentro daquilo que elas realmente pensam para conseguir liderar da melhor forma» (P5)

Para P1 o acompanhamento empático e o operativo são essenciais para que ele mantenha o seu comportamento exploratório ativo, o que, do ponto de vista da importância das interações na organização, é particularmente significativo. O discurso de P2, por sua vez, revela a importância que dá ao sentido das coisas e à necessidade de os seus subordinados as entenderem; por isso, o modo como os acompanha está associado à dimensão lógica das 
operações, mesmo no que concerne ao estilo de acompanhamento que thes proporciona e ao significado que este tem para se manter ativo na sua missão. E P3 assinala que é mais importante a percepção que os subordinados têm acerca desse suporte empático do líder do que a própria presença deste. O P4 relaciona o manter ativo o seu comportamento exploratório enquanto líder com a importância de estabelecer relações empáticas com os subordinados, procurando colocar-se na perspectiva destes. De sublinhar ainda o discurso de P5, que refere que na medida em que se aproxima dos seus subordinados e com eles se envolve, assim mais se sente capaz de realizar a sua missão.

\subsection{Suporte de familiares, amigos e pares}

O suporte social é apresentado como outra estratégia dos participantes, podendoser desempenhado pela família, os amigos ou os pares. Os participantes referem expressamente que sentem esse apoio da família e dos pares, sendo que P3, P4 e P5, os três participantes mais novos, explicitam o apoio dos amigos. No conjunto das respostas, o suporte familiar é claramente o mais evidenciado, já que três líderes casados (P1, P2 e P5) o referem explicitamente como um espaço onde se sentem escutados. A importância dada ao suporte familiar evidencia que, neste processo de transição, são muitos os focos de tensão e as necessidades de contenção emocional que estes indivíduos experimentam. Ao mesmo tempo, revela que no contexto organizacional não existem ferramentas que possam ajudar os líderes nesses processos (ou que, existindo, estes não os conhecem ou não recorrem a eles) e promover as suas competências para melhor gerirem estes desafios.

\footnotetext{
«partilhamos, quando há dificuldades (...) estando com a minha mulher e com o meu filho, tento abstrair-me de tudo (...) mesmo em casa, a minha mulher diz-me: 'levas tudo com calma'» (P1)

«necessidade de partilhar com alguém, com próximos, amigos», referindo ainda «há coisas que ajudam - a partilha na família e com os colegas (...) mas claro que não faço com subordinados» (P2)

«sinto necessidade de partilhar com alguém, com os próximos, com os amigos», sublinhando: «não ganhamos nada em nos isolar» [...]; «a partilha mútua pode até relaxar-me» (P3)

«pedir ajuda a alguém (...) a única maneira foi desabafar com amigos» (P4) «tento apoiar-me na minha família e amigos, que dão conselhos importantes. E mesmo no grupo do trabalho». Em relação à chefia: «muitas vezes não utilizo a solução que me dão, mas a partir daquilo eu ouço mais facilmente e posso construir uma solução que me pareça ajustada; é, sim, uma ferramenta que utilizo» (P5)
}

De sublinhar que P1 encontra apoio no seu núcleo familiar e, ao mesmo tempo, é ele mesmo suporte para a sua família, nos moldes em que o é na organização, revelando assim coerência entre os dois ambientes. Por sua vez, P2 distingue, de um modo evidente, a relação que mantém com os seus pares e familiares da relação que mantém com os seus subordinados. P3 destaca a importância da partilha no sentido de manter os seus níveis de motivação e de criatividade ativos, sendo que também P4 entende a partilha como algo 
necessário, perante as dificuldades que possam condicionar a sua atividade de líder neste processo de transição. Este participante, quando se refere em particular aos desafios vividos na relação com a sua chefia, refere o recurso à rede de suporte, o que sugere que esta já terá sido mobilizada (note-se o uso do verbo no modo passado: "foi"). Assim, percebe-se que, por um lado, no contexto da organização, este líder não encontrou meios que the permitissem integrar algumas das suas dificuldades e, por outro, que então o suporte dos amigos foi fundamental. Por sua vez, o discurso de P5 revela como o grupo de trabalho, assim como o lider, podem ser fonte de apoio, no sentido de regularem o sistema de exploração de um membro da equipa (em relação aos colegas) e de um subordinado (o participante, que também ele é lider). Diz que para além de recorrer à rede de apoio fora do trabalho, também se apoia nas suas chefias, referindo-se ao district manager como figura de suporte.

As estratégias apresentadas pelos líderes revelam que estes estão conscientes da importância dos processos dinâmicos no trabalho (GABARRO; ATHOS, 1976), tanto assim que sublinham que ouvir, compreender e apoiar os subordinados é essencial. De facto, é deste modo que os subordinados mais facilmente permanecem na sua área de competência (SIEGEL, 1999) sem ativar o sistema de autodefesa dos líderes, que os poderia levar ao evitamento, à luta ou à desorientação (BRANDÃO; HENRIQUE; MIGUEZ, 2016). Cremos ser esta a estratégia fundamental assumida pelos nossos participantes. Em síntese, é evidente no discurso dos líderes a importância da dimensão emocional, sobretudo no que concerne ao relacionamento com os subordinados; abrem-se assim portas para que essa importância seja concedida também ao cuidado dos líderes consigo próprios, pois, além do mais, dessa forma estarão seguramente mais aptos para a realização da sua importante missão.

«a gestão emocional é muito importante e para tal importa estar próximo, muito mais do que atingir objetivos e resultados [...] dá logo outro sentido às coisas e passa com muita facilidade outras coisas que queremos comunicar. A estratégia é esta, este lado emocional, que estamos juntos e que somos uma família» (P2)

\section{Conclusão}

A presente investigação mostra que, não obstante o facto de os líderes estudados tenderem a reconhecer a capital importância da componente emocional no seu relacionamento com os subordinados, os mesmos mostram que privilegiam mais os seus processos mentais do que os emocionais. Tanto assim que as suas estratégias para manter ativo o seu comportamento exploratório no processo de transição que estão a vivenciar estão mais focadas em processos mentais (autorreflexão e relaxamento) e menos em processos emocionais (consciência e coerência emocional).

A vivência dos cinco participantes que aqui foram focados, permite-nos melhor 
perceber as dinâmicas que caracterizam o processo de transição para uma posição de liderança em contexto organizacional, dando voz à idiossincracia de cada participante e considerando os diferentes contextos onde cada um se integra (e.g., trabalho, família, pares). Percebemos, assim, o papel das contingências de cada participante (e que remetem para esses vários contextos) e como estas entram em jogo no processo de transição estudado.

Este trabalho tem limitações que importa considerar. Desde logo, a ausência de recolha de informação junto dos subordinados dos participantes, um feedback que acrescentaria valor à investigação. Seria importante atestar e qualificar as estratégias apresentadas pelos participantes, ou seja, investigar o tema a partir do ponto de vista dos subordinados. Estudos futuros deverão ainda considerar as vivências de lideres do género feminino e explorar se os participantes estão no processo de transição para a sua primeira experiência de liderança em contexto organizacional.

Este estudo sugere que os líderes em processo de transição poderão beneficiar de programas de desenvolvimento que permitam um melhor reconhecimento e valorização dos seus estados emocionais, incluindo o medo associado aos processos de liderança. Isso poderá aumentar a sua janela de tolerância e, assim, potenciar o seu desempenho enquanto líderes, com qualidade de vida, na medida em que mantém o comportamento exploratório ativo.

Sendo certo que a exploração e a caracterização das estratégias adoptadas no processo de transição para uma posição de liderança permite-nos melhor compreender como é vivida essa transição desenvolvimental, num dos principais contextos (co-construidos) do ser humano - as organizações de trabalho - a compreensão desta transição requer que se considere simultaneamente a dinâmica completa do self nesse processo (e.g., activação do sistema de defesa do self). Dessa forma, poderemos melhor apoiar as pessoas ao longo deste percurso, para que se possam concretizar, permitindo e potenciando a concretização daqueles que as rodeiam.

\section{Referências}

ALMEIDA, B.; BRANDÃO, C. Liderança e desafios. O medo e o comportamento exploratório no processo de transição para uma posição de liderança. In: 8 Congresso Ibero-Americano em Investigação Qualitativa, 2019, Lisboa. Vol. 3. Lisboa: Ludomedia, p. 467-476. Disponível em: https://proceedings.ciaiq.org/index.php/CIAIQ2019/article/view/2304. Acesso em: 14 jul. 2019.

AMADO, J. Manual de investigação qualitativa em educação. Coimbra: Universidade de Coimbra, 2014.

BARDIN, L. Análise de conteúdo. Lisboa: Edições 70, 2011. 
BARKOULI, A. Organizational leaders' experience with fear-related emotions: A critical incident study. 2015. (PhD) -, Antioch University, Antioch.

BARKOULI, A. Organizational leaders' experience with fear-related emotions: A critical incident study. 2015. (PhD Program in Leadership and Change) -, Antioch University, Antioch.

BOWLBY, J. Attachment and Loss. London: Pimlico, 1969/1997.

BOWLBY, J. Attachment and Loss. London: Pimlico, 1973/1998.

BOWLBY, J. Attachment and Loss. London: Pimlico, 1980/1998.

BRANDÃO, A. M. Entre a vida vivida e a vida contada: a história de vida como material primário de investigação sociológica. Configurações, 3, p. 83-106, 2007.

BRANDÃO, C. O Desempenho Individual de dirigentes de topo da Administração Pública Portuguesa: um contributo para o desenvolvimento de uma taxionomia comportamental e motivacional. 2010. (Doutoramento em Psicologia) - Psicologia, Universidade do Porto, Porto.

BRANDÃO, C.; HENRIQUE, C.; MIGUEZ, J. Building a relationship with the supervisor: An exploratory study. In: ROCHA, Á.;CORREIA, H., et al (Ed.). New Advances in Information Systems and Technologies. Advances in Intelligent Systems and Computing. Springer, Cham., 2016.

EDVARDSSON, B. Service breakdowns: A study of critical incidents in an airline. International Journal of Service Industry Management, 3, n. 4, p. 17-29, 1992.

FONSECA, L.; ARAÚJO, H. C.; SANTOS, S. Sexualities, teenage pregnancy and educational life histories in Portugal: Experiencing sexual citizenship? . Gender and Education, 24, n. 6, p. 647-664, 2012.

GABARRO, J.; ATHOS, J. Interpersonal Relations and Communications. Englewood Cliffs, NJ: Prentice-Hall, 1976.

GAITER, D. J. Facets of Leadership. Neurodiagnostic Journal, 53, n. 4, p. 323-327, 2013.

GORDON, A.; YUKL, G. The Future of Leadership Research: Challenges and Opportunities. German Journal of Human Resource Research, 18, n. 3, p. 359-365, 2004.

GREENBERG, L. S. Terapia focada nas emoções. Lisboa: Coisas de Ler, 2011.

GUBA, E. G.; LINCOLN, Y. S. Competing paradigms in qualitative research. In: DENZIN, N. K. e LINCOLN, Y. S. (Ed.). Handbook of qualitative research. Thousand Oaks, CA: Sage, 1994. p. pp.105-117. 
HEARD, D.; LAKE, B. The attachment dynamic in adult life. British Journal of Psychiatry, 149, p. $430-438,1986$.

HEARD, D.; LAKE, B. The challenge of attachment for caregiving. London: Karnac Books, 1997.

HEARD, D.; LAKE, B.; MCCLUSKEY, U. Attachment Therapy with Adolescents and Adults: Theory and Practice Post Bowlby. Revised Edition ed. London: Karnac Books, 2012.

ILIES, R.; NAHRGANG, J. D.; MORGESON, F. P. Leader-member exchange and citizenship behaviors: A meta-analysis. Journal of Applied Psychology, 92, n. 1, p. 269-277, 2007.

MCCLUSKEY, U. To Be Met as a Person: The Dynamics of Attachment in Professional Encounters. London: Karnac Books, 2005.

ÖHMAN, A. Fear and anxiety: Overlaps and dissociations. In: LEWIS, M.;HAVILANDJONES, J. M., et al (Ed.). Handbook of Emotions. New York: Guilford, 2008. p. 709-729.

ORVIS, K. A.; RATWANI, K. L. Leader self-development: A contemporary context for leader development evaluation. The Leadership Quarterly, 21, n. 4, p. 657-674, 2010.

PAULILO, M. A. S. A pesquisa qualitativa e a história de vida. Serviço Social em Revista, 2, n. $135-148,1999$.

POPPER, M.; MAYSELESS, O. Back to basics: applying a parenting perspective to transformational leadership. The Leadership Quarterly, 14, p. 41-65, 2003.

SALOVEY, P.; MAYER, J. D. Emotional intelligence. Imagination, Cognition \& Personality, 9, n. 3, p. 185-211, 1990.

SANDELOWSKI, M. Real qualitative researchers do not count: The use of numbers in qualitative research. Research in Nursing \& Health, 24, n. 230-240, 2001.

SANTOS, F.; PERES, S.; BRANDÃO, C., 2018, Fortaleza (Brasil). Considerações metodológicas no estudo da liderança feminina. 175-184.

SIEGEL, D. J. The developing mind: Towards a neurobiology of interpersonal experience. New York: The Guilford Press, 1999.

SILVA, A.; BARROS, C.; NOGUEIRA, M.; BARROS, V. Conte-me a sua história: Reflexões sobre o método de história de vida. Estudos de Psicologia, 1, n. 25-35, 2007.

SVENINGSSON, S.; ALVESSON, M. Managing managerial identities: Organizational fragmentation, discourse and identity struggle. Human Relations, 56, p. 1163-1193, 2003. 
VINCE, R. Action learning and organizational learning: Power, politics and emotion in organizations. Action Learning: Research and Practice, 1, n. 1, p. 63-78, 2004.

WOOD, R. E.; BANDURA, A. Impact of conceptions of ability on self-regulatory mechanisms and complex decision making. Journal of Personality and Social Psychology, 56, p. 407415, 1989. 